\title{
KURTHEN (Hermann), BERGMANN (Werner), ERB (Rainer), eds., Antisemitism and Xenophobia in Germany after Unification
}

New York-Oxford, Oxford University Press, 1997, 318 p. (bibliogr., tablx., index)

\section{Doris Bensimon}

\section{OpenEdition}

\section{Journals}

Édition électronique

URL : http://journals.openedition.org/assr/20422

DOI : $10.4000 /$ assr.20422

ISSN : $1777-5825$

Éditeur

Éditions de l'EHESS

Édition imprimée

Date de publication : 31 décembre 2000

Pagination : 154-155

ISBN : 2-222-96698-1

ISSN : 0335-5985

Référence électronique

Doris Bensimon, « KURTHEN (Hermann), BERGMANN (Werner), ERB (Rainer), eds., Antisemitism and Xenophobia in Germany after Unification », Archives de sciences sociales des religions [En ligne], 112 I octobre-décembre 2000, document 112.80, mis en ligne le 19 août 2009, consulté le 21 septembre 2020. URL : http://journals.openedition.org/assr/20422 ; DOI : https://doi.org/10.4000/assr.20422

Ce document a été généré automatiquement le 21 septembre 2020.

(C) Archives de sciences sociales des religions 


\section{KURTHEN (Hermann), BERGMANN (Werner), ERB (Rainer), eds., Antisemitism and Xenophobia in Germany after Unification}

New York-Oxford, Oxford University Press, 1997, 318 p. (bibliogr., tablx., index)

\section{Doris Bensimon}

\section{RÉFÉRENCE}

KURTHEN (Hermann), BERGMANN (Werner), ERB (Rainer), eds., Antisemitism and Xenophobia in Germany after Unification, New York-Oxford, Oxford University Press, 1997, 318 p. (bibliogr., tablx., index)

1 La chute du mur de Berlin suivie de l'unité retrouvée de l'Allemagne de l'Ouest et de l'Allemagne de l'Est pose des problèmes politiques et économiques à la démocratie allemande. Liberté et respect des droits de l'homme sont les valeurs essentielles de toute démocratie. L'unification des deux Allemagnes a suscité, au début des années 1990, des craintes en Europe et aux États-Unis. Dirigée par le sociologue Hermann Kurthen, une équipe d'une quinzaine de chercheurs allemands et américains, sociologues, historiens, spécialistes en sciences politiques et économistes, a analysé sondages, documents et media comparant l'attitude des populations des deux Allemagnes réunies à l'égard de l'antisémitisme et de la xénophobie. Leur impressionnant projet a été soutenu par le Centre de Recherche sur l'Antisémitisme de l'Université technique de Berlin ainsi que par plusieurs universités américaines.

2 La première partie de l'ouvrage analyse un ensemble de sondages menés de 1989/1990 à 1994/1995 dans les deux parties de l'Allemagne. Les auteurs y distinguent l'antisémitisme de la xénophobie. 
3 Pendant cinquante ans, la République fédérale d'Allemagne (RFA) a mené une politique de diffusion de connaissances condamnant le régime national-socialiste et le génocide des juifs. Elle a admis la culpabilité de l'Allemagne hitlérienne et mis l'accent sur l'éducation aux valeurs démocratiques des régimes politiques occidentales. Les Allemands de la R.F.A. nés après la guerre ont été éduqués dans cet esprit. En grande majorité, ils connaissent les crimes nazis et les condamnent. Pourtant, l'antisémitisme demeure latent. Depuis les années 1970-1980 de vifs débats opposent les historiens sur la responsabilité du peuple allemand dans les crimes commis par le régime nationalsocialiste.

4 La République démocratique allemande (RDA) a condamné le national-socialisme. Mais les communistes prétendaient qu'ils formaient la fraction du peuple allemand qui avait résisté au fascisme. Selon eux, la persécution des juifs s'inscrivait dans l'ensemble des crimes commis par le régime hitlérien. En grande majorité les jeunes Allemands de l'Est éduqués dans l'esprit communiste n'étaient pas antisémites mais l'antisionisme doctrinal prenait le relais de l'antisémitisme.

5 L'unification des deux Allemagnes a pour conséquence un renforcement de la prise de conscience de l'identité nationale allemande. En Allemagne unifiée, à l'Ouest comme à l'Est, de vifs débats sur le devoir de mémoire partagent la population. Selon les sondages, un Allemand sur deux voudrait « tirer un trait » sur le passé culpabilisant de l'Allemagne hitlérienne. Chacun des quatre chapitres de cette première partie de l'ouvrage comporte en annexe la totalité des sondages utilisés ainsi que l'analyse statistique des réponses. Les $\mathrm{AA}$. admettent que les résultats sont complexes et ambivalents, mais ce matériel publié est d'une grande utilité pour des études comparatives avec d'autres pays européens.

6 La deuxième partie du livre est consacrée aux mouvements, groupes et organisations qui diffusent l'antisémitisme et la xénophobie. Depuis la chute des régimes communistes de l'Europe de l'Est, des réfugiés, demandeurs d'asile affluent en Allemagne. Les Allemands de l'Est deviennent xénophobes. Certains groupes passent à la violence physique. Leurs actions s'inscrivent dans la montée des mouvements d'extrême-droite qui exploitent les difficiles changements sociaux, économiques et politiques qu'affrontent les Allemands de l'Est après la réunification. L'apprentissage de la liberté et du sens de la responsabilité individuelle est un long processus loin d'être achevé.

7 En Allemagne comme ailleurs, xénophobie et antisémitisme sont le cheval de bataille des mouvements et partis d'extrême-droite. En annexe figure une chronologie des actes commis contre les juifs et les étrangers après la chute du mur de Berlin de 1989 à 1994.

8 L'historienne autrichienne, Brigitte Bailer-Galanda consacre un article à l'évolution du révisionnisme en Allemagne et en Autriche. Elle met en évidence les liens des négationnistes allemands avec leurs collègues français et la création d'un réseau international soutenu par la presse d'extrême-droite et internet. Le sociologue américain Elliot Neaman étudie les relations entre mouvements d'extrême-droite et de la Nouvelle Droite en Allemagne et ailleurs, soulignant le passage d'idéologies racistes dans des partis qui se considèrent comme de nouveaux conservateurs. Ces articles sont sérieusement documentés par des références aux discours et aux media ainsi qu'aux statistiques concernant l'importance numérique de tels groupes en Allemagne. 
9 La dernière partie du livre s'intéresse aux réactions contre l'antisémitisme et la xénophobie. En Allemagne, mais aussi dans d'autres pays, le public est alerté des incidents par les media, surtout s'ils dépassent la violence verbale. Les partis politiques combattent avec les moyens légaux les droites extrémistes. L'opposition d'une partie du public allemand ainsi que la crainte des réactions des pays étrangers renforcent le contrôle des groupes extrémistes par la justice allemande. Mais la xénophobie, le rejet d'immigrés illégaux même s'ils se présentent comme demandeurs d'asile est un fait européen.

Dès 1979, mais surtout depuis la chute du mur, de nombreux juifs originaires de l'exUnion soviétique sont arrivés à Berlin. Divisée entre les différents courants du judaïsme, la communauté officielle s'interrogeait sur les modalités d'accueil et les nouvelles relations entre les juifs de l'Ouest et leurs coreligionnaires de l'Est. À cette époque, la riposte à l'antisémitisme ne semble pas avoir été la préoccupation majeure de la judaïcité berlinoise. Cependant l'ensemble des contributions à l'ouvrage s'arrête en 1994/1995. Et depuis le contexte politique ainsi que tous les mouvements migratoires pouvant provoquer xénophobie, antisémitisme et fanatisme ont changé.

11 Les éditeurs de ce volume sont conscients de cette limitation dans le temps. Ils lancent un appel à la poursuite de recherches comparatives. Par sa richesse en informations, statistiques et références documentaires, cette publication constitue un excellent départ pour de nouvelles recherches. Les AA. espéraient le tassement des tendances racistes. L'actualité dément leur relatif optimisme. 